\title{
La transfiguración de Jesús: Adelanto de su Resurrección. (Mc 9,1-10 par.)
}

\author{
ANÁLISIS HISTÓRICO-TRADICIONAL*
}

Estrechamente relacionado con un vaticinio autoanastasiológico o preanuncio de su resurrección por Jesús ${ }^{1}$ relatan los tres primeros Evangelistas el evento de la Transfiguración (Mc 9,1-10par). Lo hacen, por lo demás, tras la enseñanza del Maestro sobre las condiciones del seguimiento ${ }^{2}$, que completa la primera profecía de su pasión, muerte y resurrección ${ }^{3}$ :

* Además de los comentarios (infra), Cf.: K.L. SchmidT, Der Rahmen der Geschichte Jesu, Berlin 1919 (repr. Darmstadt 1964), 222-25; J. BLINZLER, Die neutestamentlichen Berichte über die Verklärung Jesu (NA, XVII. 4), Münster 1937; ID., Verklärung Jesu: LThK X 709s; J. HÖLlER, Die Verklärung Jesu, Freiburg 1937; E. DABRowsKI, La Transfiguration de Jésus, Roma 1939, 4-46; H. RIESENFELD, Jésus transfiguré (ASNU 16), Kopenhagen 1947, 243-306; A. FEUILLET, Les perspectives propes à chaque évangeliste dans les récits de la Transfiguration: Bib 39 (1958) 281-301; H. WALTENSWEILER, Die Verklärung Jesu (AThANT 33), Zürich 1959; M. SABBE, La rédaction du récit de la Transfiguration: "La venue du Messie" (RechBib 6), Tournai 1962, 65-100; D. M. BECK, Transfiguration: IDB IV 686s; A. M. RAMSEY, La gloire de Dieu et la transfiguration du Christ (LD 40), Paris 1965, 123-58; X. LÉONDufour, La Transfiguration de Jésus: "Études d'Évangile", Paris 1965, $84-122$ (trad. españ., Madrid 1982, 23-119); H. SchÜRMANN, Lukas, I 553-67 (bibliogr.); CH. ScHÜTz, La Transfiguración de Jesús: MS III. 2 (Madrid 1971), 103-8; J. M. NüTZEL, Die Verkärungserzählung im Markusevangelium, Würzburg 1973, espec., 10-199 (bibliogr.); W. LIEFELD, Theological motifs in the Transfiguration narratives: "New dimensions in the NT" (ed. R. N. Longenecker- M. C. Tenney), Grand Rapids 1974, 162-79; P. DE SuRGY, Transfiguración: VTB 912-14; Ph. PARkINS, Resurrection. New Festament witness and contemporary reflection, Garden City (N. Y.) 1984, 95-99; J. A. McGuckIn, The Transfiguration of Christ in Scripture and Tradition, Lewiston (N. Y.) 1986, 1-97. Más bibliografía (cf. R. PESCH, Markus II 82-84) ofrecemos en las páginas siguientes.

1. Mc 9,9=Mt 17,9.

2. Mc 8,34-38par.

3. Mc 8,31-33par. 


\section{Mt 16,28-17,9}

En verdad os digo, que hay algunos de los aquí presentes, quienes no gustarán la muerte hasta que vean al Hijo del hombre venir en su reinado (v. 28). Y después de seis dias toma Jesús a Pedro y Santiago y Juan su hermano, y les lleva a un monte alto aparte (v. 1). $Y$ fue transfigurado ante ellos; y brilló su rostro como el sol, deviniendo sus vestidos blancos como la luz (v. 2). Y he aquí que se les apareció Moisés y Elías, conversando con él (v. 3).

Y respondiendo Pedro dijo a Jesús: Señor, bueno es que estemos aquí; si quieres, haré aquí tres tiendas: Una para ti, una para Moisés, una para Elías (v. 4).

Mientras él hablaba, he aquí que una nube luminosa les cubrió con su sombra;

$\mathrm{Y}$ he aquí que de la nube surgió una voz, que decía: ¿Este es mi Hijo amadísimo, en quien me complací! ¡Escuchadle!' (v. 5). Y al oírlo los discípulos cayeron sobre su rostro y temieron mucho $(v$. 6). Y se acercó a Jesús y, tocándoles, dijo: Levantaos y no temáis (v. 7). Levantando entonces sus ojos, a nadie vieron sino a él, a Jesús solo (v. 8).Y, bajando ellos del monte, les ordenó Jesús diciendo: A nadie digáis la visión, hasta que el Hijo del hombre resucite de entre los muertos (v.9).

\section{Mc 9,1-10}

$Y$ les dijo: En verdad os digo, que hay algunos de los aqui presentes, quienes no gustarán la muerte hasta que el reinado de Dios venido en poder (v. 1). Y después de seis días toma Jesús a Pedro y a Santiago y Juan, y les lleva a un monte alto, aparte solos. $Y$ fue transfigurado ante ellos (v. 2); y sus vestidos devinieron tan blancos, que ningún lavandero sobre la tierra puede blanquearlos así (v. 3). Y se les apareció Elías con Moisés, y conversaban con Jesús (v. 4).

Y respondiendo Pedro, dice a Jesús: Rabbí, bueno es que estemos aquí,

haremos tres tiendas: Una para ti, una para Moisés, una para Elías (v. 5). No sabía qué decir pues estaban temerosos (v. 6).

Y sucedió que una nube les cubrió con su sombra;

y de la nube surgió una voz, que decía: " Este es mi Hijo amadísimo! jEscuchadle! (v. 7).

$\mathrm{Y}$ de repente mirando a su alrededor, no vieron a nadie sino a Jesús solo con ellos (v. 8). Y, bajando ellos del monte, les ordenó que $a$ nadie, contaran lo que vieron, sino cuando el Hijo del hombre resucitase de entre los muertos (v. 9). Y conservaron el suceso para sí, indagando qué significaba lo de resucitar de entre los muertos (v. 10).

\section{Lc 9,27-36}

Os digo verdaderamente: Hay algunos de los aquí presentes, quienes no gustarán la muerte hasta que vean el reinado de Dios (v. 27). Pasaron unos ocho días después de estas palabras, y tomando a Pedro y a Juan y a Santiago subió al monte a orar (v. 28). $Y$ sucedió mientras oraba, que el aspecto de su rostro (devino) otro y su vestidura (devino) blanca resplandeciente (v. 29). Y he aquí que dos hombres conversaban con él: Eran Moisés y Elías (v. 30), quienes, aparecidos en gloria, hablaban de su éxodo que se cumpliría en Jerusalén (v. 31). Pedro y sus compañeros estaban cargados de sueño; pero despertándose vieron su gloria y a los dos hombres, que estaban con él (v. 32). Y sucedió que, al separarse aquéllos de él, dijo Pedro a Jesús: Maestro, bueno es que estemos aquí,

haremos tres tiendas: Una para ti, una para Moisés, una para Elías. No sabía lo que decía (v. 33).

Mientras decía esto, tuvo lugar una nube y les cubrió con su sombra, temiendo ellos al entrar en la nube (v. 34). $Y$ de la nube surgió una voz, que decía: 'Este es mi Hijo, el elegido! ¡Escuchadle!' (v. 35).

Y cuando pasó la voz, quedó

Jesús sólo.

$\mathrm{Y}$ ellos guardaron silencio, y en aquellos días a nadie anunciaron lo que vieron ( $\mathrm{v}$. 36). 
La misma sinopsis de la triple narración evangélica muestra ya, que los relatos de Mt y Lc siguen muy de cerca al de su fuente literaria (Mc). No sin modificarla - sobre todo Lc - con propios datos estilísticos y, ocasionalmente, ampliarla: Lc más que Mt. ¿Qué interpretación teológica refleja cada redacción evangélica? ¿Late tras ésta una tradición pre-redaccional (Cf. $2 \mathrm{Pe}$ 2,16-18) o primitiva? Y, en caso afirmativo, ¿se remonta esa tradición a un evento histórico de Jesús? ¿Cómo fue interpretado éste por aquella tradición y cuál fue su significado prístino? A estos interrogantes intenta responder el siguiente análisis histórico-tradicional del triple relato evangélico.

\section{La redacción evangélica}

El relato de los tres Evangelistas refleja una estructura literaria, globalmente homogénea: Tras la introductoria profecía de Jesús sobre la "visión" del "reinado de Dios" (Mc+Lc) o del "Hijo del hombre" (Mt) por "algunos" de sus discípulos antes de "gustar la muerte" 1, sigue la narración central sobre la "transfiguración" y teofanía mesiánica 2; concluido todo el relato con la prohibición de Jesús de divulgar lo acaecido antes de "resucitar de entre los muertos" 3 , o mencionando la praxis de aquellos sobre ese secreto 4 . ¿Qué interpretación teológica trasluce cada una de las tres redacciones evangélicas?

1) El evangelista MARCos nos ofrece el relato más antiguo ${ }^{5} y$, sin duda, es la fuente literaria de las otras dos narraciones evangélicas. ¡Lo que no significa, que aquél se limite a reproducir el evento prístino! Marcos, por el

1. Mc 9,1par.

2. Mc 9,2-8par.

3. Mc 9,9-Mt 17,9.

4. Lc $9,36 \mathrm{~b}$.

5. Para su análisis, además de los comentarios (M.-J. LAGRANGE, Marc 228-34; E. LOHMEYER, Markus 173-81; J. SCHMID, Markus ${ }^{9}$ 169-73: trad. españ., 244-50; V. TAYLOR, Mark ${ }^{2}$ 386-92: trad. españ., 459-67; R. PESCH, Markus II 69-84; J. GNILKA, Markus II 29-39), cf. los estudios de: E. LOHMEYER, Die Verklärung Jesu nach dem Markus-Evangelium: ZNW 21 (1922) 185-215; J. BLINZLER, o.c., 10-14.78s; E. DABROWSKI, o.c., 7-70; G. H. BOOBYER, St. Mark and the Transfiguration story, London 1942, 58-87; H. RIESENFELD, o.c., 281-88; A. FeUILLET, a.c., 288-89; H. WALTENSWEILER, o.c., 30-36; M. SABRE, o.c., 90s; T. A. BURKYLL, Mysterious revelation, Ithaca (N.Y.) 1963, 156-64; C. MAsson, La transfiguration de Jésus (Mc 9,2-13): RThPh 14 (1964) 1-14; A. M. RAMSEY, o.c., 139-48; X. LÉON-DufOUR, o.c., 114 (trad. españ. 111); L. RIVERA, El misterio del Hijo del hombre en la Transfiguración (Mc 9,29): RBib 28 (1966) 19-34.79-89; ID., El relato de la Transfiguración en la redacción del evangelio de Marcos: RBib 31 (1969) 143-58. 229-43; M. BALAGUÉ, La Transfiguración: CB 24 (1967) 83-122. 356-65; J. NÜTZEL, o.c., 87-166. 236-56; E. NARDONI, La transfiguración de Jesús y el diálogo sobre Elías según Mc, Buenos Aires 1976; J. A. McGuckin, o.c., 23-97. 
contrario, redactó literariamente e interpretó teológicamente una tradición evangélica. En efecto:

a) Su redacción literaria refleja una. narración profundamente marcada por el vocabulario y estilo del Evangelista 6 . Pues si características marcianas son tanto la reiterada construcción paratáctica (="kai":y) de la frase 7 como el uso del presente histórico ${ }^{8}$ y del participio ${ }^{9}$, también lo es la imposición del "secreto mesiánico" ${ }^{10}$ y el uso de semitismos ${ }^{11}$, así como la construcción "resucitar de entre los muertos" 12 y el "hóti" (=porque) recitativo 13; caracterizan asimismo al vocabulario marciano el uso de los verbos "mirar alrededor" y "retener" 14 , de los adv. "muy" 15 y "aparte" 16 así como de la expresión "está bien" 17. Todos estos datos reflejan la indiscutible impronta literaria de Marcos. Quien insertó su relato, por lo demás, en un contexto literario bien preciso: Antes de la instrucción de Jesús acerca del retorno de Elías 18 y tras su enseñanza - "les dijo" - sobre las condiciones para seguirle ${ }^{19}$, inicia la narración marciana, estrechamente vinculada - “y les dijo“- con esa previa enseñanza del Maestro (v.1). Por otra parte, la unidad literaria de su relato está garantizada tanto por la localización geográfica -

6. A este respecto, cf.: J. C. HAwkIns, Horae Synopticae, Oxford 1909, 10-15. 114-53; M. J. LAGRANGE, Marc LXVII-CVI; M. ZERWICK; Untersuchungen zum Markus-Stil. Rom 1937; V. TAYLOR, Mark ${ }^{2}$ 44-66 (trad. españ., 67-88); M. REISER, Syntax und Stil des Markusevangeliums (WUNT 11), Tübingen 1984. Más concretamente sobre este relato de Mc, cf. J. BLINLER, o.c., 79.

7. Mc 9,1.2a.b.3.4.5a.b.7a.b.8.9.10: cf. J. C. HAwkINS, o.c., 150-52; M-J. LAGRANGE, o.c., LXIX; M. ZERWICK, o.c., 1-21; V. TAYLOR, o.c., 57 (trad. españ., 78).

8. Mc 9,2a. b.5: cf. J. C. HAWKINS, o.c., 143-48; M.-J. LAGRANGE, o.c., LXIXs; M. ZERWICK, o.c, 49-57; V. TAYLOR, o.c., 46 (trad. españ., 69).

9. Mc 9,1.4. 5. 7. 8. 9. 10: cf. M.-J. LAGRANGE, o.c., LXIX; V. TAYLOR, o.c., 46 (trad. españ., 68s).

10. Mc 9,9: cf. M. ZERwick, o.c., 25s; V. TAYLOR, o.c., 122-24 (trad. españ., 137s); G. MinetTE DE TILESSE, Le secrète messianique dans l'Évangile de Marc (LD 47), Paris 1968, espec., 39-73. 249-51.

11. Cf. M. -J. LAGRANGE, o.c., LXXXIV-CVI; TAYLOR, o.c., 55-66 (trad. españ., 77-88). Entre los cuales: El participio presente (Mc 9,3.7: cf. M. BALCK, An aramaic approach to the

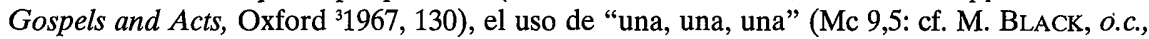
108) y la construcción "si no" (Mc 9,8): cf. M. BLACK, o.c., 114.

12. Ex nekrõn anasténai: $\mathrm{Mc} 9,9$ (= Mc 4, Mt 0, Lc 2).

13. Mc 9,1: cf. M. ZERWICK, o.c., 41s.

14. Periblépomai: Mc 9,8 (=Mc 6, Mt 0, Lc 1): cf. C. J. HAwKIns, o.c., 12; Kratéo: Mc 9,10

(=Mc 15, Mt 12, Lc 2): cf. C. J. HawkIns, o.c., 13.

15. Lian: Mc 9,3 (=Mc 4, Mt 4, Lc 1).

16. Kat'idian: Mc 9,2 (=Mc 7, Mt 7, Lc 2).

17. Kalós estin: Mc 9,5 (=Mc 6, Mt 4, Lc 1).

18. Mc 9,11-13.

19. Mc 8, 31-38. 
"un monte"- del evento (vv. 2. 9) como por la inclusión del verbo "ver" (vv. 1. 9). Y si el reiterado uso de ese verbo (vv. 1. 8. 9) indica ya la unidad temática de la narración, también delata su específico género literario de relato epifánico ${ }^{20}$, corroborado tanto por el uso del verbo "aparecer" (v. 4) como por los teofánicos vocablos de la "nube" y la "voz" celeste (v. 7). Un relato, por lo demás, cuya estructura literaria o composición interna ${ }^{21}$ no es difícil detectar: La inclusión dada por el nombre "Jesús" (vv. 2. 8) y su reiterada mención (vv. 4-5) muestra la unidad literaria del relato central sobre la transfiguración "en un monte" (vv. 2-8); introducido aquel por la conexionada (="y") profecía sobre la "visión" del "reinado de Dios venido en poder" (v. 1), y concluido con la imposición del secreto - "bajando del monte"- a los tres discípulos sobre "lo que había visto" (v. 9); un epílogo del Evangelista sobre el cumplimiento del secreto por aquéllos y su indagación sobre el significado de "resucitar de entre los muertos" (v. 10) cierra el relato marciano, cuya estructura literaria es pues ésta:

-Introducción (v. 1)

-La Transfiguración de Jesús en "un monte" (vv. 2-8) localización geográfica (v. 2a)

el evento epifánico (vv. 2b-7)

Jesús transfigurado con "Elías y Moisés" (vv. 2b-4)

reacción de Pedro (vv. 5-6)

Proclamación teofánica (v. 7)

solos con Jesús (v. 8)

-Conclusión: Secreto, "bajando del monte" (v. 9)

-Epílogo (v. 10).

Este rápido análisis sobre la redacción literaria del relato por Marcos, muestra que el Evangelista le imprimió la impronta personal de verdadero autor.

b) A la luz de aquel análisis debemos ahora detectar su interpretación teológica del evento. Ya el vocablo temático — "ver"— así como el mencionado género literario del relato (cf. supra) muestra que éste fue interpretado fundamentalmente como una epifanía de Jesús: ¿En qué sentido? Quien "fue transformado" o transfigurado por Dios "ante" los tres discípulos (v. 2b) asumió ya entonces la sustancialmente nueva "forma" o el personalmente nuevo aspecto anastásico del Resucitado que, en calidad de tal, efectiva-

20. Así con R. PesCh, o.c., 70; J. Gnilka, o.c., 32. También: M. Dibelius, Die Formgeschichte des Evangeliums, Tübingen ${ }^{5} 1966,275$ s; A. FEUILLET, o.c., 282; E. LOHMEYER, o.c., 175; J. SCHMID, o.c., 170 (trad. españ. 247); X. LÉON-DufOuR, o.c., 114 (trad. españ., 111).

21. Cf. L. F. RiverA, a.c., (1969), 148s; E. NARDONI, o.c., 136s. 
mente "se manifestó en otra forma" o aspecto a dos discípulos ${ }^{22}$, siendo asimismo sus "muy blancos vestidos" (v. 3) semejantes a la "túnica blanca" vestida por el pascual mensajero del Resucitado ${ }^{23}$. Al "Jesús" anastásicamente "transformado" por Dios o anticipadamente revestido por la "resplandeciente" gloria del Resucitado 24 "vieron" pues los tres discípulos (v. 8); a quienes, por ello, prohibió el Maestro divulgar "lo que vieron", antes de que Él "resucitase de entre los muertos" (v. 9), y en cuya visión del prolépticamente resucitado se cumplió por tanto la introductoria profecía de "ver el reinado de Dios venido en poder" (v. 1) o experimentar su poderoso dominio sobre la muerte ${ }^{25}$. ¿Una "visión" fugaz o experiencia transitoria, que sólo se consolidaría por el posterior encuentro con el Resucitado! Se comprende pues la incomprensión de los tres discípulos o testigos oculares de la Transfiguración sobre "lo que significase resucitar de entre los muertos" (v. 10): ¡Sólo a la luz de la Resurrección podían comprender el significado de su prolepsis anastásica o de la Transfiguración! No hay pues duda: Marcos interpretó fundamentalmente la transfiguración de Jesús como una anticipada epifanía anastasiológica del "Maestro" o la proléptica manifestación del Resucitado a sus tres discípulos, quienes anticipadamente "vieron" su gloria o potencia salvífica y, personificada en ésta, el adelanto del potente "señorío de Dios" sobre la muerte. Una interpretación global del evento, añadámoslo, específicamente completada por la de la mesiánica filiación divina de Jesús o la identificación del Transfigurado. Así lo refleja ya la estructura literaria del relato marciano (cf. supra) sobre el evento central (vv. 2b-7): Iniciado con la "transfiguración", culmina con la teofánica proclamación del "amadísimo Hijo" de Dios y su exhortación a "escucharle" ${ }^{26 .}$ En esa proclamación, que

22. Mc 16, 12. Este texto es ciertamente post-marciano (cf. J. HuG, La finale de l'Évangile de Marc [Mc 16, 9-20], Paris 1978, 61-67) y, por ello, sólo al nivel de la redacción final de Mc vale el paralelismo mencionado, subrayado también por A. FEUILLET, a.c., 285. El verbo "metamorphoûn" (v. 26) esprexa pues "un cambio muy profundo" (M.-J. LAGRANGE, o.c., 228; así también E. LOHMEYER, o.c., 174) y, a la luz del mencionado contexto pascual, formula una "metamorfosis" anastásica, no escatológica o apocalíptica: Contra J. BEHM, Metamorphéo: ThWNT IV 765; J. SCHMID, o.c., 170 (trad. españ., 247); R. PESCH, o.c., 72.

23. Mc 16,5. Todo el v. 3 refleja "la gloria del Resucitado": R. PESCH, o.c., 73.

24. La transfiguración o "metamorfosis de Jesús es una prolepsis de su resurrección": R. PeSCH, o.c., 72; cf. A. FeUillet, a.c., 285. Los mencionados contactos literarios de Mc 9,2-3 con su narración pascual muestra cuán erróneo es afirmar, que su relato "no parece tener conexión alguna con la resurrección" de Jesús (T. A. BURKILL, o.c., 160). ¡La tiene y muy estrecha! Pues, por lo demás, los verbos "metamorphóthe" o fue transfigurado (v. 2b) y "egérthe" o fue resucitado (Mc 16,6) son pasivos divinos, que en ambos casos expresan la acción de Dios: Así con R. PESCH, o.c., 72. 533.

25. S. Sabugal, Abbá. La Oración del Señor, Madrid 1985, 515. Indecisos: D. E. NineHAM, The Gospel of St. Mark, London 1963, 236; J. ScHMID, o.c., 160 (trad. españ., 245). 
trasluce una confesión cristológica - "éste es" - de la Comunidad marciana, adquiere sin duda un punto álgido "el evangelio sobre Jesucristo, Hijo de Dios" (Mc 1,1) o la gradual revelación de la dignidad mesiánica y filiación divina de Jesús. Pues la inicial proclamación bautismal del "amadísimo Hijo" de Dios y por Él enviado en calidad de su "Hijo amado" 27, luego reconocido incluso por los endemoniados como "el Hijo de Dios" y en calidad de tal confesado finalmente por el "centurión" romano ${ }^{28}$, es ahora confirmada "¡éste es!"- y completada con el imperativo divino a "escucharle". Lo que significa: "El Hijo amadísimo" de Dios es el mesiánico Maestro divino, que debe ser escuchado o cuya enseñanza es normativa. ¿Qué enseñanza? El previo contexto literario del relato marciano ${ }^{29}$ y con él estrechamente vinculado (cf. supra) muestra, que aquel imperativo divino se refiere a la instrucción del Maestro sobre las condiciones para "seguirle" o devenir sus discípulos: "Autorrenunciarse" o negar ser salvador de la propia historia, para confesar a Jesús como "el Mesías" 30 o el único Salvador y, por cierto, tomando "la propia cruz" o perdiendo "la propia vida por causa de Él y del evangelio", para "salvarla" 31. La mencionada interpretación teológica de Marcos está pues dominada por una clara intencionalidad catequética sobre el seguimiento de Jesús o la exhortación a "escuchar" la enseñanza del mesiánico Maestro divino sobre las imprescindibles condiciones para seguir a Quien, con su transfiguración o anticipada resurrección, señaló la meta de cuantos por el sendero de la autorrenuncia y la cruz le sigan: ¡Pueden estar seguros de que "verán" ya - como los tres discípulos- al Transfigurado o experimentarán, en situaciones de cruz, la anticipada gloria del Resucitado! ¿Es necesario subrayar la vigente actualidad de esta interpretación marciana, para todo seguidor o discípulo de Jesús?

2) El relato de MATEO sigue de cerca a su fuente marciana ${ }^{32}$. No sin abreviarla u ocasionalmente ampliarla y, en todo caso, interpretándola teológicamente como verdadero autor de su narración. En efecto:

26. Mc 9,7. Esa proclamación constituye "el culmen de todo relato": E. LOHMEYER, o.c., 176; cf. W. GRUNDMANN, Markus 182.

27. Mc 1,$11 ; 12,6$.

28. Mc 3,$11 ; 5,7 ; 15,39$.

29. Mc 8,34-38.

30. Mc 8,29.

31. Mc 8,34-38.

32. Para su análisis, además de los comentarios (M.-J. LAGRANGE, Matthieu 334-37; A. SCHLATTER, Matthäus 521-31; P. BonNARD, Matthieu 253-57: trad. españ., 378-83; J. SCHNIEwind, Matthäus 192s; W. GrundmanN, Matthäus 402-4; O. DA SPINEToli, Matteo 425-31; R. H. GUNDRY, Matthew 342-46; R. FABRIS, Matteo 366-69), cf. los estudios de: J. BLINZLER, o.c., 5-10. 77s.; E. DABRowsKI, o.c., 4-7; H. RiesenFeld, o.c., 288s; A. FeuIlLET, a.c., 299-99; M. SABBE, e.c., 87-89; A. M. RAMSEY, o.c., 149s; X. LÉON-DifouR, o.c., 114s (trad. españ., 111s); J. S. NÜTZEL, o.c., 275-78. 
a) el relato mateano delata por doquier el cuño de su redacción literaria, con datos de su vocabulario y estilo característicos 33: El rostro de Jesús "brilló como el sol" y blanquearon sus vestidos "como la luz" 34, hablando "Moisés y Elías con" quien es no ya el "Maestro" (Mc) sino "el Señor" 35 así como el "Hijo amadísimo" de Dios y su mesiánico Siervo "en quien se complació" 36; se comprende pues que temiesen "mucho" los discípulos, tranquilizados sin embargo por el "¡no temáis!" de Jesús (vv. 6-7), cuya "visión” no deben divulgar "hasta que el Hijo del hombre sea resucitado (=egérthe) de entre los muertos" (v. 9) ${ }^{37}$. Con éstos y otros datos estilísticos redactó Mateo su relato, cuyo contexto es idéntico al de $\mathrm{Mc}{ }^{38}$. Su unidad literaria está garantizada por el reiterado empleo del nombre "Jesús" 39 así como por la explícita o latente mención de los tres discípulos ${ }^{40} \mathrm{y}$, principalmente, por las numerosas inclusiones: La construcción "hasta que" y la mención del "Hijo del hombre", así como el uso del verbo "ver" y del sustantivo "visión" 41. Este vocablo y el reiterado uso de aquel verbo ${ }^{42}$ indican ya la unidad temática de la narración mateana y su género literario específico: Quienes "verán al Hijo del hombre", luego contemplaron al Transfigurado como "Señor" y, en calidad de tal, "vieron a Jesús", cuya "visión" 43 fue por tanto una Kyriofanía 44. Eso narra el Evangelista. Cuyo relato central sobre la transfiguración de Jesús o el "Señor" en "un monte alto" (vv. 1-7) está conexionado (="y") e introducido por la profecía sobre la futura visión del "Hijo del hombre" (Mt

33. A este respecto, cf.: J.C. HAwINs, o.c., 3-10. 30-35. 154-73; M.-J. LAGRANGE, Matthieu LXXI-CVII; U. LUZ, Das Evangelium nach Matthäus, I (EKK, I. 1), Neukirchen-Vluyn 1985, 31-56; W. SCHENK, Die Sprache des Matthäus, Göttingen 1987. Más concretamente sobre este relato de Mt, cf. J. BLINZLER, o.c., $77 \mathrm{~s}$.

34. Mt 17,2. Tanto el verbo "lámpo" (brillar: Mt 3, Mc 0, Lc 1) como el vocablo "to phôs" (luz: Mt 7, Mc 1, Lc 2) son característicos de Mt (cf. U. Luz, o.c., 43. 53; W. ScHENK, o.c., 457.459), siendo suya la expresión "como el sol": Mt 13,43.

35. Mt 17,3-4. La sustitución de "Maestro" (Mc 9,5) por "Señor (Mt 17,4) es intencionada, pues el uso tanto de "Kyrios" (Mt 48, Mc 6, Lc 36) como del vocativo "Kyrie" (Mt 29, Mc 1, Lc 24) es característico de Mt: cf. V. LuZ, o.c., 43; W. SCHENK, o.c., 307s.

36. Mt 17,5. Esta última adicción de Mt — "en quien me complací" — a su fuente (Mc) reproduce literalmente la mateana proclamación baustismal (Mt 3,17) y, sin duda, es redacción del Evangelista: cf. W. SCHENK, o.c., 302.

37. Característico de Mt es el uso del verbo "egéiro" (Mt 37, Mc 18, Lc 18: cf. U. LuZ, o.c., 39; W. ScHENK, o.c., 209), para designar la resurrección de Jesús (Mt 9, Mc 2, Lc 2)

38. Tras la instrucción de Jesús a sus discípulos sobre las condiciones para seguirle (Mt 16,24-27) y antes de la respectiva sobre el retorno de "Elías" en la persona de "Juan Bautista" (Mt 17,10-13).

39. Mt 17, 1. 4. 7.8.9.

40. Mt 17,1. 2b. 4. 5. 6. 7. 8. 9.

41. Mt 16,28; 19,9 .

42. Mt 16,$28 ; 17,8$.

43. Mt 16,28; 17,2. 4. 8. 9. 
$16,28)$, concluyéndose con la imposición del secreto de Jesús a los discípulos sobre "la visión" y, por cierto, "bajando del monte" (v. 9); ésta es pues la estructura literaria o composición interna 45 del relato mateano:

-Introducción $(16,28)$

-Transfiguración de Jesús en "un monte muy alto" $(17,1-8)$

localización geográfica (v. 1)

el evento kyriofánico (vv. 2-8)

la transfiguración (vv. 2-3)

reacción de Pedro (v. 4)

la proclamación teofánica (vv. 5-7)

"¡Éste es mi Hijo...!" (v. 5)

reacción de los discípulos (vv. 6-7)

solos con "Jesús" (v. 8)

-Conclusión: "Bajando del monte..." (v. 9)

Estos análisis muestran que Mateo no reprodujo simplemente a su fuente literaria, sino le imprimió el sello de su redacción personal.

b) Y esa redacción trasluce una peculiar interpretación teológica del Evangelista. En efecto, tanto el característico género literario del relato (cf. supra) como el intencionado uso del título cristológico "Señor" en su parte central 46 muestra, con claridad, que la narración mateana es fundamentalmente una Kyriofanía. Y literarios indicios objetivos permiten especificarla. Pues si el brillante "rostro como el sol" de Jesús transfigurado y "sus vestidos blancos como la luz" evocan irresistiblemente el fulgurante "aspecto como el relámpago" y el "vestido blanco como la nieve" del "ANGEL" o mensajero pascual ${ }^{47}$, la reiterada tranquilización de las mujeres por dicho mensajero y por el RESUCITADO del sepulcro - “¡no temáis" - reasume literalmente la de los tres discípulos — "no temáis"- por JESUs transfigurado ${ }^{48}$;

44. Es impreciso calificar de "Cristofanía" el relato de Mt: Contra X. LÉON-Dufour, o.c., 114 (trad. españ., 112).

45. Cf. R. FABRIS, o.c., 367.

46. Mt 17,4 (cf. supra, n. 35). La característica sustitución mateana de "Maestro" por "Señor" y su preferente uso del vocativo "Señor" en boca de los Discípulos (cf. supra, n. 35) refleja el carácter confesional de ese título cristológico en la exclamación de Pedro; así con: G. BORKAMM, Enderwartung und Kirche im Matthäusevangelium: "Überlieferung und Auslegung im Matthäusevangelium" (WMANT 1), Neukirchen-Vluyn ${ }^{4} 1965,13-47$ : 38s. G. STRECKER, Der Weg der Gerechtigkeit (FRLANT 82), Göttingen ${ }^{3} 1971,123-26: 124 ;$ J. D. KINGSBURY, Matthew: Structure, Christology, Kingdom, London 1976, 103-13: 103-4. 111; W. SCHENK, o.c., 307-8: 307.

47. Mt 17,2b; 28,3.

48. Mt 28,5. 10a; 17,7b. 
cuyo precepto de no divulgar "la visión" tenida, "hasta que el HIJO DEL HOMBRE resucite (=egérthe) de entre los muertos", anticipa también el posterior anuncio pascual - "resucitó" (=egérthe)— del ángel sobre el RESUCITADO o vencedor de la muerte ${ }^{49}$. No hay pues duda: También Mateo interpretó fundamentalmente la transfiguración de Jesús como anticipación o prolepsis de su resurrección, y, por tanto, "el Señor" transfigurado es adelanto del Señor resucitado, siendo pues "la visión" de Aquél una Kyriofanía anastasiológica. ¡Se comprende que ésta no sea inteligible antes de Pascua, es decir, "hasta que el Hijo del hombre resucite de entre los muertos" o reine sobre la muerte! Pues en "la visión" anticipada del Resucitado o "Señor" de la muerte por los tres discípulos vio cumplida sin duda el Evangelista la profecía de Jesús sobre la futura "visión", por "algunos de" aquéllos, del "Hijo del hombre venido en su reinado" o señorío sobre los muertos 50 . Eso es pues, ante todo, el mateano "Jesús" transfigurado: El "Señor", en cuya transfiguración anticipó la victoria del Resucitado sobre la muerte e inauguró "el reinado" del "Hijo del hombre" sobre los muertos. No sólo eso. La teofánica identificación de Jesús por Dios con su "Hijo amadísimo, en quien se complació", reproduce literalmente la respectiva del Bautismo ${ }^{51}$ y la completa con la deuteronómica exhortación - “iescuchadle!"- sobre el "Profeta" mosaico ${ }^{52}$. El "Señor" transfigurado y prolépticamente resucitado se identifica por tanto no sólo con "el Hijo" natural de Dios, cuya proclamación celeste sobre su filiación divina confirma la respectiva confesión de Pedro ${ }^{53}$, sino también con el mesiánico Rey davídico y el profético-mesiánico "Siervo de Dios" ${ }^{54}$ así como con el escatológico Profeta mosaico 55; y, por cierto, superior a Moisés, no sólo en calidad de natural "Hijo amadísimo" de Dios (cf. supra) sino también porque "Moisés y Elías hablaban con" Quien "vino

49. Mt 17,$9 ; 28,7$.

50. Mt 17,9;16,28.

51. Cf. supra, n. 36.

52. Mt 3,17+17,5 (=Sal 2,7; Is 42,1; Dt 18,5). Para el análisis de la cita mateana, cf. R. H. GundRY, The use of the OT in St. Matthew's Gospel (Suppl. NT 18), Leiden 1967, 22-32. 36s.

53. Mt 17,5; 16,16. Así con: W. GrundmanN, o.c., 402; J. D. KingSBURY, o.c., 68. Para la central concepción cristológica de Mt sobre la natural filiación divina de Jesús, cf.: J.D. KINGSBURY, o.c., 40-83; F. HAHN, Huiós: EWNT III 912-36: 920; W. SCHENK, o.c., 301s.

54. Mateo reitera la identificación de Jesús sobre el mesiánico "Siervo de Dios": cf. Mt 8, 16-17 (=Is 53,5); 12, 15-21 (=Is 42,1-4).

55. Los temas de los "seis días" y del "monte alto" (v. 1) así como del "brillante rostro" de Jesús (v. 2), de "la nube" y la "voz" celeste (v. 5) evocan irresistiblemente los respectivos de la teofanía en "el monte" Sinaí a Moisés (Éx 24, 15-16; 34,29s), cuyo "rostro [era] como el rostro del sol" (SifréNúm 140): cf. A. SCHLATTER, o.c., 527; O. DA SPINETOLI, o.c., 428s; J. D. KINGSBURY, o.c., 90; R. H. GUNDRY, Matthew 342-44. 
a plenificar (la revelación divina contenida en) la Ley y los Profetas" 56: ¡No tanto a "Moisés y Elías" así como a los maestros del Judaísmo - "los escribas y fariseos"-, cuanto a ese "Hijo amadísimo" y fiel Siervo de Dios así como su plenificante Revelador mesiánico "deben escuchar" desde ahora los tres discípulos y, en ellos representada, la Comunidad mateana! En el contexto de la marcada polémica antijudaica, que recorre todo el evangelio de Mateo 57 , ese imperativo divino — “زescuchadle!_” trasluce probablemente la intención mateana de "sustituir a Moisés con Cristo" 58 y, más exactamente, el magisterio judaico con el respectivo del "Señor" resucitado, prolongado y actualizado - "enseñadles" - universalmente o "a todas las gentes" por la Iglesia 59. La mencionada interpretación teológica de Mateo desemboca pues en una catequética exhortación a que los fieles de su Comunidad sustituyan el magisterio de Moisés en el Judaísmo o en el antiguo Israel, por el del Señor en su Iglesia o el verdadero Israel: ¡No debe tener otro "Maestro” que "Cristo" 60. Una exhortación actual para todo cristiano, tentado frecuentemente - hoy como ayer - a sustituir la enseñanza del Evangelio por la de maestros -Marx, Freud...- de nuestro mundo: ¡Sólo la fiel audición e incondicional adhesión al mensaje de Jesús — el Maestro- condiciona y garantiza nuestra esencial misión de evangelizar tanto a los paganos como a los neopaganos de nuestro tiempo, así como de enseñar a todos los hombres la única Palabra que, además de iluminar el sentido de la existencia humana o esclarecer sus enigmas, "conduce a la Vida"!

56. Mt 17,3; 5,17. Así con: J. D. KingSBURY, o.c., 90; R. FABRIS, o.c., 369. Es inexacto decir que en Mt 17, 1-5 el Evangelista presenta a Jesús "como el nuevo Moisés» (M. SABRE, o.c., 87-89; cf. también: A. FeuIllet, a.c., 301; R. H. GuNDRY, Matthew 345), pues en el contexto de la mateana cristología mosaica o tipología cristológica de Moisés (cf. J. JEREMIAS, Moysés: ThWNT IV 874s; F. HAHN, Christologische Hoheitstitel [FRLANT 83], Göttingen ${ }^{3} 1966,400-2$; J. D. KINGSBURY, o.c., 89-92; W. A. MEEKs, Moses in the NT: IDBSuppl. 605-7: 606; H. SEEBASS, Moisés: DTNT III 110-13: 111) se subraya la superioridad de Jesús respecto del Legislador antiguo: cf. G. D. KILPATRICK, The origins of the Gospel acc. to St. Matthew, Oxford 1966, 108; J. M. GIBBS, The Son of God as the Tora Incarnate in Matthew: StEv 4 (1968) 38-46: 44; S. SABUGAL. La embajada mesiánica de Juan Baustista, Madrid 1980, 44-46; J. D. KINGSBURY, o.c., 89-92: 91s; W. SCHENK, o.c., 147.

57. R. HuMmel, Die Auseinandersetzung zwischen Kirche und Judentum im Matthäusevangelium (BETh 33), München 1966; U. LUZ, o.c., 70-72; cf. también: W. TRILling, Das wahre Israel (StANT 10), München 1964, 90-95. 221s (trad. españ., Madrid 1974, 130-37. 318s); G. STRECKER, o.c., 99-118.

58. O. DA SPINETOLI, o.c., 429.

59. Mt 28, 19-20. Es pues exacto afirmar que, en su relato, Mateo presenta al Jesús transfigurado como el "Maestro único y definitivo de la humanidad": A. FEuILLET, a.c., 298.

60 . Mt 23,10. 
3) También Lucas elaboró su relato ${ }^{61}$ sobre el respectivo de su fuente (Mc) literaria ${ }^{62}$, imprimiéndole el cuño de su redacción estilística y de su interpretación teológica.

a) La redacción literaria del tercer Evangelista, en efecto, delata constantemente su vocabulario y estilo característicos ${ }^{63}$ : los verbos "orar" $64 \mathrm{y}$ "deber" 65, "callarse" y "anunciar" 66, los sustantivos "gloria" 67, "Jerusalén" 68 y "preceptor" 69, así como las características expresiones "sucedió" + verbo finito ${ }^{70}$ " "al" + infinitivo ${ }^{71} \mathrm{y}$ "decir a" ${ }^{72}$; a las que se añaden las típicas expresiones "y he aquí" e "y ellos" 73 y "dos hombres" 74 a todo ello se suma la considerable ampliación del relato central de Mc por Lc (vv. 30-33a) 75, quien suprimió asimismo el "secreto" final impuesto por Jesús a los tres discípulos 76 así como la conversación sobre el retorno de "Elías" 77. Lucas

61. Además de los comentarios (M. -J. LAGRANGe, Luc 271-75; J. SCHMID, Lukas 169s: trad. españ., 244-46; W. GRUNDMANN, Lukas² 191-93; H. SchÜRMANN, Lukas I 553-67: 55356; I. H. MARSHALL, Luke 380-89; J. A. FitzMYER, Luke I 791-804; DA SPINETOLI, Luca 33742), cf. los estudios de: J. BLINZLER, o.c., 14-17. 79-81; E. DABROWSKI, o.c., 10-13; H. RIESENFELD, o.c., 290s: A. FEUILLET, a.c., 289-92; M. SABBE, e.c., 92-95; A. M. RAMSEY, o.c., 150-53; H. Conzelmann, Die Mitte der Zeit, Tübingen ${ }^{5} 1964$, 50-52; X. LÉON-Dufour, o.c., 115s (trad. españ., 112s); W. Dietrich, Das Petrusbild der lukanischen Schriften, Suttgart 1972, 104-16; J. M. NüTZEL, o.c., 289-99. Para la crítica textual del relato lucano, cf. J. BLINZLER, o.c., 14-17.

62. Así con: H. SchÜrmanN, o.c., 559. 562. 563; F. NEIRYNCK, La matiére marcienne dans l'évangile de Luc: "L'Évangile de Luc" (ed. F. Nierynck), Gembloux 1973, 157-201: 17375: J. A. FitzmYER, o.c., 791s. Las divergencias de Lc respecto a Mc no postulan el uso de otra fuente literaria (contra varios comentaristas y otros autores, citados por H. SCHÜRMANN, o.c., 563, n. 72; F. NIERYNCK, e.c., 173, n. 77) ni de "tradiciones orales" prelucanas (contra I. H. MARSHALL, o.c., 381), pues aquellas divergencias "son todas características lucanas": H. SCHÜRMANN, o.c., 563.

63. A este respecto, cf.: J. C. Hawkins, o.c., 15-29. 35-51. 174-97; H. J. CADBURY, The style and litterary method of Luke, Cambridge 1920; A. PluMMER, Luke XLI-LVII; M. -J. LAGRANGe, Luc XCV-CXXVIII; J. A. FITMYER, o.c., 109-14. Más concretamente sobre este relato de Lc, cf.: J. BLINZLER, o.c., 79-81; J. A. FITZMYER, o.c., 792.

64. Proseúchesthai: vv. 28. 29 (=Mt 15, Mc 10, Lc 19), con referencia a la oración de Jesús: Lc 3,21; 5,16; 6,12; 9,18. 28. 29; 11,1;22,44; cf. 23, 34.43.

65. Méllein: v. 31 (=Mt 10, Mc 2, Lc 12+Act 34).

66. Lc 9,36b: Sigân (=Mt 0 Mc 0, Lc 3) y epangélein (=Mt 8, Mc 5, Lc 11+Act 16).

67. Dóxa: vv. 31.32 (=Mt 7, Mc 3, Lc 13).

68. Ierousalém: v. 31 (=Mt 2, Mc 0, Lc 27).

69. Epistátes: v. 33 (=Mt 0, Mc 0, Lc 7).

70. Egéneto+verbo finito: vv. 28. 33 (=Mt 5, Mc 2, Lc 22).

71. En tô+infin.: v. 29. 33. 34. 36 (=Mt 3, Mc 2, Lc 32).

72. Eîpen pros: v. 33 (=Mt 0, Mc 5, Lc 99).

73. Kai idoú: v. 30 (=Mt 17, Mc 0, Lc 17); kai autói: vv. 30. 36 (=Mt 0, Mc 4, Lc 26).

74. Andres dyo: vv. 30.32 (=Mt 0, Mc 0, Lc 5+Act 3).

75. Esos vv. reflejan "en todas sus partes la redacción lucana": H. SCHÜRMANN, o.c., 559; así también F. NIERYNCK, e.c., 173.

76. Mc 9,9=Mt 17,9.

77. Mc 9, 11-13=Mt 17, 10-13. 
redactó pues "con alto grado de libertad" a su fuente 78 . Le sigue de cerca, sin embargo, en el contexto de la perícopa: Tras la enseñanza de Jesús a "todos" sus seguidores sobre las condiciones del seguimiento ${ }^{79}$ sigue el relato acerca de la "visión" del Jesús pre-"glorificado" en el monte ${ }^{80}$, antes del respectivo sobre la curación del niño endemoniado tras "bajar del monte" 81. Tanto esa localización geográfica - en "el monte" - como el incluyente y reiterado tema de la "visión" 82 aseguran pues la unidad literaria y temática del relato lucano: Quienes "verán" antes de morir "el reinado de Dios" (v. 27) fueron los que, en "el monte" anónimo, "vieron la gloria" de Jesús (v. 32) y, tras oir su proclamación mesiánica por "la voz" divina (vv. 35-36), "a nadie dijeron lo que vieron" (v. 36). Una "visión", por tanto, narra fundamentalmente la perícopa de Lucas. Cuyo género literario es pues la epifanía cristológica del "reinado de Dios", presencializado en "la gloria " del Jesús prolépticamente glorificado (cf. intra) y por "la voz" divina mesiánicamente proclamado (cf. infra). Por lo demás, no es difícil detectar la estructura literaria de la narración lucana. El tema de la "visión" prologa (v. 27) y epiloga (v. $36 \mathrm{~b})$ ciertamente al relato central (vv. 28-36a); a cuya introducción cronológica y topográfica (v. 28) ${ }^{83}$ siguen dos narraciones, delimitadas con precisión por Lucas mediante la construcción "y sucedió" + infinitivo (vv. 29a. 33a). Versa la primera sobre la proléptica "gloria" (=dóxa) del "Maestro", atestiguada por "Moisés y Elías" (vv. 29-32): Como "dos hombres" celestes o con "vestidos resplandecientes" y "blancos" atestiguarán la resurrección y ascensión de Jesús ${ }^{84}$, también aquellos "dos hombres" (vv. 30-32) fueron testigos del Jesús prolépticamente glorificado - "su vestido (era) resplandecientemente blanco"- así como de "su éxodo"-muerte, resurrección y ascensión- jerosolimitano ${ }^{85}$, cuya "gloria" pascual o anastásica prolépticamente

78. J. A. FITZMYER, o.c., 782.

79. Lc 9,23-26. El inmediato contexto antecedente no es pues "la profesión de la pasión" (Lc 9,22): Contra H. ConzelmanN, o.c., 50s (trad. españ., 89s).

80. Lc 9, 27-36: vv.27 ("vean"). 36 ("vieron").

81. Lc 9, 37-43a.

82. Lc 9,27. 32. 36 .

83. La expresión lucana "estas palabras" (v. 28a) se refiere al dicho anterior de Jesús (v. 27): cf. Act 5, 23-24a.

84. Lc 24, 4. 6.; Act 1, 10-11.

85. Si los "dos hombres" en Lc+Act representan el papel de testigos (cf. S. SABUGAL, La embajada mesiánica, 98-100: bibliogr.), el "éxodo" de Jesús (v. 31) incluye su muerte, resurrección y ascensión: cf. E. LoHSE, Lukas als Theologe der Heilsgeschichte: EvTh 14 (1954) 256-75: 263; J. G. DAvIES, The prefigurament ot the Ascension in the Third Gospel: JThSt 6 (1955) 229-33: 230s; A Feuillet, a.c., 291; S. SABugAL, o.c., 99, n. 42; J. A. FitzMyer, o.c., 800 . 
"vieron" asimismo los tres discípulos 86; una epifanía doxalógica es pues la primera narración lucana. La segunda (vv. 33-36a) se centra en la proclamación de Jesús por "la voz" (vv. 35-36) divina como "el Hijo" natural de Dios y "el Elegido" o su preanunciado Siervo mesiánico, "a quien" como nuevo Moisés "deben escuchar" desde ahora los discípulos 87; es pues una teofanía mesiánica. Ésta es, por tanto, la composición interna del relato de Lucas:

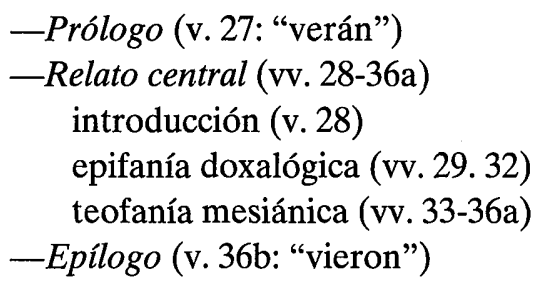

c) Este previo análisis literario nos ayuda ya en el esfuerzo por precisar, con objetividad, la interpretación teológica latente bajo esa redacción literaria del relato lucano. Digamos de inmediato, que la pre-glorificación de Jesús tiene lugar "mientras oraba" (v. 29), como lo hizo y lo hará en momentos culminantes de su ministerio: A raíz ya de su bautismo así como antes de la elección de los Doce, de la confesión de Pedro y de la enseñanza del Padrenuestro 88; se trata pues de un evento importante y, en la concepción lucana, representa - digámoslo así- como el culmen de la oracional experiencia mística de Jesús. No sólo eso. Lucas lo interpretó fundamentalmente como una "visión" o experiencia personal de los tres elegidos discípulos sobre "el reinado de Dios", presencializado en "la gloria" del Maestro anticipadamente glorificado y por Dios mesiánicamente proclamado. En el contexto de la concepción lucana, efectivamente, "el reinado de Dios" o su señorío universal fue ya inaugurado por Jesús con mesiánicos prodigios salvíficos y, mediante el libertador don del Espíritu, continúa siendo implantado en el mundo por el Señor glorificado ${ }^{89}$ : La prometida "visión" de aquel "reinado" por "algunos" discípulos (v. 27) tuvo lugar, cuando prolépticamente "vieron la gloria" (v. 32) propia del Señor exaltado (cf. supra) o la potencia salvífica de su señorío sobre la muerte; eso narra fundamentalmen-

86. Lc 9,32; cf. 24,26; Act 3,13. 15.

87. Lc 9,35 (=Is 42, 1[LXX]+Dt 18,15[LXX]): cf. Lc 23,35; Act 3,22. Para el análisis de la cita lucana, cf. M. RESE, Alttestamentliche Motive in der Christologie des Lukas (StNT 1), Gütersloh 1969, 195s.

88. Lc 3,21; 6,12; 9,18; 11,1. Sobre el puesto central de la oración en el ministerio del Jesús lucano, cf. S. SABUGAL, $A b b a ́, 210$ (bibliogr.).

89. Cf. S. SABUGAL, $A b b a ́$, 220-25; bibliografía sobre ese tema central en Lc+Act: $I b$., 220, n. 43. 
te la epifanía doxalógica del relato lucano (vv. 29-32). Completada por la teofanía mesiánica del mismo (vv. 33-36a): Aquella gloria y señorío del "Maestro", anticipadamente glorificado, es propia del mesiánico Profeta mosaico y Siervo de Dios (v. 35) o de quien "debía padecer y así entrar en su gloria", siendo efectivamente - con su resurrección y ascensión- "constituido Señor y Mesías" por el Dios que así "glorificó a su siervo Jesús" 90. Mediante la epifanía doxalógica y la teofanía mesiánica del Maestro experimentaron pues prolépticamente los tres discípulos la futura glorificación del filial Siervo de Dios, así como la consumada implantación de su "reinado". Ésta es la interpretación característica del relato marciano por el evangelista Lucas. Añadamos seguidamente que el contexto antecedente del relato lucano o la enseñanza de Jesús sobre las condiciones del seguimiento (cf. supra) refleja claramente la intencionalidad catequética subyacente a esa interpretación teológica: ¡"La gloria" del "Maestro" iluminará ya la senda y será la meta de "todos" los que le sigan, "autorrenunciándose y tomando diariamente su propia cruz" (Lc 9,23)! Una exhortación válida sin duda para el cristiano de hoy y de siempre: ¡Por el fracaso de "la cruz" al triunfo de "la gloria"!

Sintetizando estos análisis redaccionales del relato evangélico, podemos decir que los tres Evangelistas coinciden en interpretar la transfiguración de Jesús como un adelanto de su resurrección $(\mathrm{Mc}+\mathrm{Mt})$ y exaltación celeste $(\mathrm{Lc})$, así como una proléptica "visión" del "reinado de Dios" o de su señorío sobre la muerte por los tres elegidos discípulos. No sin reflejar la redacción literaria de cada Evangelista una interpretación peculiar: Culmen de la progresiva autorrevvelación de Jesús como mesiánico Hijo de Dios y Maestro divino (Mc); confirmación de su mesiánico-divina vocación bautismal y confesión de Pedro así como su proclamación de único y plenificante Revelador mesiánico (Mt); epifanía doxalógica y teofanía mesiánica del anticipadamente glorificado Siervo de Dios (Lc). ¡Sólo a ése "debe escuchar" la Iglesia o Comunidad de quienes le siguen por el sendero de "la propia cruz", jalonado ya con la gloria del Transfigurado!. 


\section{La tradición evangélica}

La fuente literaria $(\mathrm{Mc})$ de los otros dos relatos evangélicos no es creación del Evangelista, sino redacción de una previa tradición cristiana 1.

1) Un detenido análisis tradicional del relato marciano 2 muestra, en efecto, que si el texto de Mc refleja su vocabulario y estilo ${ }^{3}$, también usa muchos vocablos y expresiones del todo extraños al Evangelista. En efecto, únicos en el NT son los verbos "resplandecer" y "blanquear" (v. 3) así como el sustantivo "lavandero" (v. 3) y el adv. "de repente" (v. 8), usando sólo aquí Mc los verbos "transformar" (v. 2) y "cubrir" (v. 7), "aparecerse" y "conversar" (v. 4) 4, así como las expresiones "gustar la muerte" y "ver el reinado de Dios" (v. 1), "Elías con Moisés" (v. 4), "hacer tres tiendas" y "una... una... una" (v. 5), "a nadie vieron sino a Jesús sólo" (v. 8), "bajar del monte" y "cuando el Hijo del hombre resucite de entre los muertos" (v. 9); son asimismo únicas en el Nt las expresiones "después de seis días" y "los llevó" (v. 2), "ningún lavandero...así" (v. 3) y "estaban temerosos" (v. 6), "los cubrió una nube" y "se oyó una voz de entre la nube" (v. 7), "no contar a nadie lo que vieron" (v. 9); a la tradición premarciana se remonta también la elección de los tres discípulos (v. 2) ${ }^{5}$ y la divina proclamación mesiánica de Jesús (v. 7b) 6. Todos estos literarios indicios objetivos muestran que Mc usó una tradición evangélica, cuyo aproximado texto sería éste 7:

Y (Jesús) les dijo: En verdad os digo, hay algunos de los presentes, quienes no gustarán la muerte hasta que vean el reinado de Dios (v. 1). Y después de seis días toma Jesús a Pedro y Santiago y Juan, y los lleva a un monte alto; y fue transfigurado (por Dios) ante ellos (v. 2) y sus vestidos devinieron blancos (v. 3); y se les apareció Elías con Moisés, hablando con Jesús (v. 4). Y Pedro dijo a Jesús: ¡Maestro, bueno es estar aquí! ¡Hagamos tres tien-

1. Cf. X-LÉon-Dufour, o.c., 103-16 (trad. españ., 103-10); H. SCHÜRMANN, o.c., 563s; J. M. NÜTZEL, o.c., 87-187.

2. Cf. J. M. NÜtZEL, o.c., 87-166 (¡el autor atribuye demasiado a la redacción de Mc!).

3. Cf. supra, nn. 7-17.

4. Cf. J. BLINZLER, o.c., 78s.

5. Cf. Mc 5,37 (=Lc 8,51); 9,2 par; 14,33 (=Mt 26,37). La variabilidad marcana del artículo -sólo antes de "Pedro" (Mc 5,37; 14,33) o antes de los tres discípulos (Mc 9,2) - muestra que esa elección existía "en la tradición premarcana": R. PESCH, o.c., I 307; cf. II 71.

6. Bastante diversa de la marciana proclamación bautismal (Mc 1,11) y casi literalmente reproducida por la tradición independiente (cf. infra) de 2Pe 1,17: cf. H. ScHÜRMANN, o.c., 562. La proclamación bautismal y transfiguracional es tradicional (cf. J. HeREMIAS, Moysês: ThWNT IV 873) y se remonta a "la Comunidad jerosolimitana": E. PESCH, o.c., II 77.

7. Por no tener en cuenta varios de los mencionados datos extraños a Mc, es demasiado exiguo el relato reconstruido por J. M. NÜTzEL, o.c., 165. 
das: una para ti, una para Moisés y una para Elías! (v. 5). No sabía lo que decía, pues estaban temerosos (v. 6). Y sucedió que una nube los cubrió, y se oyó una voz de entre la nube: ¡Éste es mi Hijo amadísimo! ¡Escuchadle! (v. 7). Y de repente a nadie vieron, sino a Jesús sólo (v. 8). Y bajando del monte les dijo que a nadie contasen lo que vieron, sino cuando el Hijo del hombre resucite de entre los muertos (v. 9).

Añadamos seguidamente, que numerosos semitismos, y entre ellos, muchos arameísmos recorren prácticamente todo el relato de esa tradición premarciana. Ya el reiterado uso de la cópula "y" o de la construcción paractáctica puede ser "influencia" de la tradición aramaica, dado que aquella "es mucho más frecuente en arameo que en griego" 8; también el empleo del presente histórico (vv. 2.5) y del participio presente e imperfecto (vv. 3.4.5.7) refleja probablemente un influjo aramaico 9 . Semitismos aramaicos son asimismo el adv. "amén" o en verdad (v. 1) ${ }^{10} \mathrm{y}$ el pasivo divino "fue transformado" (v. 2) 11, el sustantivo "rabbí" o maestro (v. 5) ${ }^{12}$ y el título "Hijo del hombre" (v. 9) 13; también lo son las expresiones "no gustar la muerte" (v. 1) o no morir 14, "el reinado de Dios" y "ver el reinado de Dios" (v. 1) o participar de él 15, "una... una... una" (v. 5) 16 así como "y sucedió que una nube" + "una voz" (v. 7) ${ }^{17}$ y "una voz de [entre la] nube" (v. 7) o una voz de Dios ${ }^{18}$, siendo asimismo aramaica la proclamación mesiánica de Jesús (v. 7) ${ }^{19}$. Todos esos semitismos y arameísmos muestran que, bajo el reconstruido texto pre-marciano, late una primitiva tradición judeo-cristiana, cuya prístina forma literaria se cristalizó probablemente "en la Comunidad palestinense" ${ }^{20}$. Sobre esta tradición elaboró su relato Mc, fuente literaria de Mt y Lc:

8. M. BLACK, o.c, $130 \mathrm{~s}$.

9. Cf. M. BLACK, o.c., 130s.

10. cf. G. Dalman, Die Worte Jesu, Leipzig 21930 (repr. Darmstadt 1965), 186; STR.BILL, I 242; W. BAUMGARTNER, Hebräisch und aramäisches Lexikon zum AT, Leiden ${ }^{3} 1967$, $62 \mathrm{~b}$.

11. Tal sustituto del nombre divino "es frecuente en" el aramaico Targum palestinense al Pentateuco (=Neofiti I): A. Diez MACHO, Neophyti 1.IV, Madrid 1974,54* (textos); otros testimonios de la literatura rabínica ofrecen: G. DALMAN, o.c., 184. 383; STR.-BILL, I 443; J. JEREMIAS, Die Abendmahlsworte Jesu, Göttingen ${ }^{41967,195, ~ n . ~} 1$ (trad. españ., Madrid 1980, 220, n. 6).

12. Cf. G. Dalman, o.c., 272-76.

13. Cf. G. DaLman, o.c., 191-205: 192ss.

14. Cf. STR.-BILL., I 751s; J. BEHM, Geúomai: ThWNT I 675.

15. Cf. G. DALMAN, o.c., 75-83. 89.

16. Cf. M. BLACK, o.c., 108.

17. Cf. Éx 19,16. 19 (H) + TgPIÉx 19, 16. 19.

18. Cf. G. Dalman, o.c., $167 \mathrm{~s}$.

19. Cf. G. Dalman, o.c., 226-30: 227-29.

20. H. SCHÜRMANN, o.c., 566. A similar conclusión llega otro autor, afirmando que tras el relato evangélico late "una tradición de antigüedad remota": K. L. SCHMIDT, o.c., 225. 
El arquitectónicamente homogéneo - aunque en detalles diverso- edificio de sus tres redacciones evangélicas está pues cimentado "sobre el testimonio de los Apóstoles" ${ }^{21}$ y, en particular, de "Pedro, Santiago y Juan" (v. 1) o de quienes, entonces precisamente, "eran considerados como columnas" o sólidos soportes de la Iglesia y de su fe cristiana por la Comunidad jerosolimitana 22 .

2) A la luz de estos análisis debemos ahora interrogarnos por la interpretación teológica de la Transfiguración de Jesús, a ese nivel tradicional ${ }^{23}$. Y lo haremos sobre datos objetivos de la tradición evangélica:

a) La "transfiguración" del Maestro con "vestidos resplandecientes" en "un monte alto" y "ante" los tres discípulos "después de seis días" o al día séptimo, evocaba probablemente a la Comunidad judeo-cristiana la análoga transfiguración de Moisés, quien "subió al Monte Sinaî" con tres hombres, y tras "seis días" o "al día séptimo", le habló Dios y su "rostro devino resplandeciente" 24: Jesús es el nuevo Moisés o Mediador de la revelación divina para la Iglesia o "el Israel de Dios" (Gál 6,16). Cuya superioridad respecto de "Moisés y Elías", por lo demás, se refleja en la conversación de éstos "con Jesús" así como en el precepto divino de "escucharle" ${ }^{25} \mathrm{y}$, por cierto, sólo a Quienes es confesado - “EÉste es!"- como el natural "Hijo amadísimo" de Dios. Todos estos datos traslucen, con toda probabilidad, una confesión cristológica sobre la filiación divina de Jesús; también reflejan una tácita polémica antijudaica, subrayando la superioridad del Transfigurado respecto de esas dos figuras culminantes de la religiosidad judaica, así como su definitiva sustitución por Quien es el único Mediador de la revelación de Dios.

b) Otro auxiliar objetivo de aquella interpretación nos lo ofrece el testimonio de un autor neotestamentario sobre la Transfiguración:

"Os hemos dado a conocer el poder y la Venida de nuestro Señor Jesucristo, ...después de haber visto con nuestros ojos su majestad. Porque recibió de Dios Padre honor y gloria, cuando la sublime Gloria le dirigió esta voz:

21. M.-J. LAGRANGE, o.c., 233.

22. Gál 2,9: cf. A. VIARD, Epître aus Galates, Paris 1964, 46; H. SCHLIER, Der Brief an die Galater (Meyerk 7), Göttingen ${ }^{4} 1965$, 78s (trad. españ., Salamanca 1975, 95); F. MusSNER, Der Galaterbrief (HerdersThKNT 9), Freiburg 1974, 120s; F. E. BRUCE, Commentary on Galatians, Grand Rapids (Mich.) 1982, 122s.

23. Cf. J. M. NÜTZEL, o.c., 167-77.

24. Éx 24, 1.9.15-16; 34, 29s.

25. No tanto la tipología mosaica de Jesús cuanto su superioridad respecto de Moisés subraya ese precepto de "escucharle" (=Dt 18,15 [LXX]), al nivel de la tradición evangélica: cf supra, n. 6 . 
'Éste es mi Hijo amadísimo, en quien me complazco'. Nosotros escuchamos esta voz venida del cielo, estando con él en el monte santo" $(2 \mathrm{Pe} 1,16-18)^{26}$.

Los evidentes contactos literarios con la mencionada tradición evangélica, - "haber visto" y la "voz", el "monte" y la casi literal reproducción de la proclamación mesiánica-, así como sus no menos claras divergencias sobre todo la omisión de "¡escuchadle!"- son indicios seguros de que su autor evoca una tradición independiente sobre la transfiguración de Jesús 27. En el testimonio visual sobre la glorificación del "Hijo amadísimo" por Dios, "en el monte santo", se enraiza ese anuncio del autor sagrado a su comunidad cristiana sobre "el poder" y la Venida" parusíaca de Quien fue efectivamente "constituido Hijo de Dios con poder... por su resurrección de entre los muertos" 28, y cuya "venida" final "esperan" los fieles ${ }^{29}$ ¡En la "gloria" del Señor transfigurado se adelantó "el poder" del Señor resucitado! Por lo demás, "el monte santo" (v. 18) es como tal designado por el Salmista "el monte Sión" 30, devenido en la tradición neotestamentaria ese "monte grande y alto" símbolo de la "Jerusalén celestial" o morada de los ya glorificados 31: De quienes, por haber participado de la resurrección y glorificación de Jesús, están cubiertos con "vestidos blancos" 32 o semejantes a los "vesti-

26. Para su análisis, cf.: J. Blinzler, o.c., 17-18. 30-31. 71-76; J. Höller, o.c., 135-42; E. Dabrowski, o.c., 43-46; A. M. RAMSEY, o.c., 154-57; C. SPICQ, Les Étitres de saint Pierre, Paris 1966, 218-23; K. SCHELKLE, Die Petrusbriefe (HerdersThKNT XIII. 2), Freiburg ${ }^{4} 1976$, 196-99; F. Mussner, Petrus und Paulus-Pole der Einheit (QD 76), Freiburg 1976, 66s.

27. Así con: J. Blinzler, o.c., 71s; J. Höller, o.c., 142; E. DABrowsKi, o.c., 45s; M. SABBE, e.c., 75-75. 83 y otros; contra J. A. FITZMYER, o.c., 797. La referencia de 2Pe 1, 16-18 a la Transfiguración es reconocida por: J. BLINZLER, o.c., 30-31. 71s; J. HöLLER, o.c., 140-42; E. DABRowSKI, o.c., 44-46 (con varios autores ahí citados); A. M. RAMSEY, o.c., 156; R. RIESENFELD, o.c., 265; C. SPICQ, o.c., 219. 221; H. SCHÜRMANN, o.c., 564; K. SCHELKLE, o.c., 198s; F. MUSSNER, o.c., 67; A. FITZMYER, o.c., 796s. Que Jn 12,28 evoque Mc 9,7par y, por tanto, atestigüe otra tradición independiente sobre la Transfiguración (así X. LÉON-DUFOUR, o.c., 11619: trad. españ., 113-17; también los comentarios de W. BAUER, M.-J. LAGRANGE, E. C. Hoskyns, R. Bultmann, R. E. Brown y S. A. Panimolle: ad loc.) es del todo improbable: El paralelismo sinóptico y joanneo del contexto precedente (Mc 8,31. 34-35par=Jn 12, 23.2526: cf. X. LÉON-DUfOUR, o.c., 117s: trad. españ., 114s) queda contrastado por la ausencia del verbo central "fue transfigurado" en el texto joanneo, cuya pasada glorifiación ("edóxasa") del "nombre" del Padre (v. 12b) se refiere sin duda al previo "signo" de la resurrección de Lázaro, realizada por Jesús "para la gloria de Dios" (Jn 11,4.40). Así con: J. HölleR, o.c., 1; E. DABRowsKI, o.c., 31 y varios comentarios joanneos (P. ScHANZ, Tübingen 1884, 24; TH. CALMET, Paris 1904, 126), entre los cuales últimamente R. SCHNACKENBURG, Das Joannesevangelium, II (HerdersThKNT IV. 2), Freiburg 1971, 486 (trad. españ., 480).

28. 2 Pe 1,16; Rm 1,4; cf. Act 13,35; Hebr 1,5; 5,5.

29. 1 Tes 1,10 .

30. Sal 2,$6 ;$ cf. 3,$4 ; 14,1 ; 42,3 ; 47,1 ; 98,9$.

31. Apoc 21,10; cf. 14,1; Hebr 12,22.

32. Apoc 4,4; 6,11; 7,9; cf. 3,5. 18. 
dos blancos" del Jesús transfigurado (cf. supra). Hacia esa meta se dirigen quienes aún peregrinan aquí en la tierra o "esperan" la anunciada "venida" del "Hijo de Dios" resucitado de entre los muertos 33; pues, como Jesús "fue transformado" gloriosamente (cf. supra), también sus fieles "nos vamos transformando de gloria en gloria, conforme a la acción del Señor [mediante el] Espíritu" 34. Estos contactos literarios y teológicos de los escritos neotestamentarios con la tradición evangélica sobre la transfiguración de Jesús muestran que a ese nivel tradicional, aquélla fue interpretada probablemente como un adelanto de la resurrección y glorificación de Jesús así como un preanuncio del glorioso estado de los salvados. No sólo esto. Tanto aquella prolepsis anastasiológica y doxalógica como este preanuncio estuvieron al servicio de una catequesis escatológica o exhortación apremiante a los fieles: Espoleados a seguir transformando la propia vida, -ipor la "acción del Espíritu"!-, en la espera del retorno parusíaco del Señor y de subir al "monte alto" o al "santo monte" de "la Jerusalén celestial"...

c) Una interpretación de actualidad vigente. Pues si nos exhorta a "escuchar" la enseñanza del único Maestro de la revelación divina, también alecciona - hoy como ayer- a cuantos corremos el riesgo de "acomodarnos a este mundo" o secularizarnos 35 e instalarnos en sus realidades terrestres, olvidando nuestra esencial condición de peregrinantes ${ }^{36}$ y la necesidad de dejarnos "transformar" por el Espíritu de Cristo, para escalar "el santo monte" o habitar en "la Jerusalén" de los bienaventurados.

\section{El evento histórico}

¿Es la tradición evangélica sobre la transfiguración de Jesús un producto de la fe postpascual o idealización de un suceso natural, de una visión imaginaria y, en todo caso, anticipación mítica o legendaria de una aparición pascual? Así lo han valorado muchos exégetas modernos ${ }^{1}$. ¡Del todo arbitrariamente! Pues ninguno de ellos fundamentó su valoración sobre la sólida base de un científico análisis histórico-tradicional de los textos evangélicos.

33. 1 Tes 1,$10 ; 2 \mathrm{Pe} 1,16$.

34. 2 Cor 3,18; cf. Rm 12,2. A este respecto, cf. J. BEHM, Metamorphéo: ThWNT IV 76567.

35. Cf. S. SABUGAL, Liberación y secularización, Barcelona 1978, 328-62: 354ss.

36. Cf. S. SABugal, Credo. La fe de la Iglesia, Zamora 1986, 730-49.

1. Cf. J. Blizler, o.c., 90-162; V. TAYLoR, o.c., 386-88 (trad. españ. 459-61); J. GNILKA, o.c., II 38s. Una "creación de la Comunidad" primitiva, es el relato de Mc según H.-P. Müller, Die Verklärung Jesu: ZNW 51 (1960) 56-64: 60. 62s. 
El que estamos realizando nos ha guiado desde la triple redacción evangélica hasta su tradición judeo-cristiana. Y ésta, se enraiza, sin duda, en el firme subsuelo de un evento sustancialmente histórico del ministerio galilaico de Jesús 2 .

1) A ese resultado desemboca efectivamente el objetivo e imparcial enjuiciamiento de aquella tradición por algunos de los más importantes criterios de historicidad evangélica ${ }^{3}$ :

a) En favor de su historicidad sustancial aboga ya el testimonio múltiple de aquel evento, atestiguado efectivamente no sólo por las redacciones de los tres Evangelistas y por la pre-redaccional tradición evangélica, sino también por el independiente testimonio de otro autor $(=2 \mathrm{Pe})$ neotestamentario. Esos cinco testimonios postulan — no prueban - la historicidad del hecho atestiguado. Corroborada, sin embargo, por la evidente discontinuidad de aquella tradición con el Judaísmo contemporáneo: El central verbo "fue transfigurado" es desconocido tanto por los LXX como por la literatura judaica; cuya esperanza mesiánica, añadámoslo, ignoró una "transfiguración" terrestre del Mesías así como su venida en relación con "Elías y Moisés" ". La tradición judeo-cristiana sobre la transfiguración de Jesús no proviene pues del Judaísmo. ¡Tampoco és hija natural de la Comunidad postpascual!

b) Instructivo, a este respecto, es ya la casi total ausencia cristiana o de datos típicamente postpascuales en la mencionada tradición evangélica. Ésta, en efecto, usó reiteradamente muchos vocablos y expresiones —centrales muchos de aquéllos y éstas- únicos en toda la literatura neotestamentaria ${ }^{5}$ y extra-evangélicos (Act+Epístolas + Apoc) o específicamente cristianos. Extraña, sobre todo, la total ausencia de sus títulos mesiánicos característicos — "Cristo", "Señor", "Hijo de Dios"— así como de sus confesiones cristológicas respectivas: Si Jesús es designado sólo "Rabbí" o maestro (v. 5), como generalmente lo fue por sus discípulos 6, que la proclamación de la "voz" celeste sobre su filiación divina y mosaica dignidad mesiánica (v. 7)

2. Cf. J. BlinZler, o.c., 90-126; H. WALTENSweiler, o.c., 87-90; M.-J. LAGRANGE, Marc 231-34; X. LÉON-Dufour, o.c., 106s (trad. españ., 104). Una refutación objetiva de los exégetas, que niegan su historicidad, ofrecen: J. BLINZLER, o.c., 91-162; M.-J. LAGRANGE, o.c., 23133; H. SCHÜRMANN, o.c., 564-66.

3. A este respecto, cf.: J. CABA, De los Evangelios al Jesús histórico, Madrid 1971, 391403 (bibliogr.); R. LATOURELLE, L'accès à Jésus par les Evvangiles, Paris-Montréal 1978, $215-$ 39; ID., Miracles de Jésus et théologie du miracle, Montréal-Paris 1986, 73-91 (bibliogr.).

4. Cf. STR.-BILL. I 756. Es pues claro, que "aquí no se relata una esperanza del Judaísmo tardío": H. SCHÜRMANN, o.c., 566.

5. Cf. supra, par. 2.1. 
no es una clara confesión cristológica, lo refleja el hecho de que, en el contexto de éstas, el apelativo "amadísimo" está del todo ausente. La elección de "Pedro, Santiago y Juan" por Jesús (v. 2) no es producto de la tradición cristiana, en la que su evocación sigue un diverso orden $7 ; \mathrm{y}$, por lo demás, el activo papel desempeñado en la Iglesia primitiva tanto por "Juan" como por "Santiago" 8 contrasta visiblemente con el desconcertante pasivismo total de esos dos discípulos en dicha tradición evangélica: ¡No es ésta una creación de la Comunidad palestinense; cuya tradición reproduce más bien "un precedente histórico"! 9. ¿Es acaso creación de aquélla el enigmático aserto de Jesús sobre la "visión" del "reinado de Dios" por "algunos de" sus discípulos, antes de "gustar la muerte" (v. 1)? La respuesta sólo puede ser afirmada por quienes ignoren $\mathbf{u}$ olviden que "la Iglesia primitiva no inventó enigmas de Jesús, sino que - lejos de eso- los aclaró ${ }^{10}$. Tampoco es creación de la Comunidad cristiana la mención conjunta de "Elías con Moisés" así como la propuesta de "hacer tres tiendas" por Pedro (vv. 4-5), ambas ignoradas por la literatura extra-evangélica. La cual, por lo demás, desconoce totalmente el uso cristológico del verbo central "ser transformado" (v. 2) y lo aplica sólo a la existencia cristiana ${ }^{11 .}$.

Finalmente, el uso del verbo "anístemi", para expresar la resurrección de Jesús (Mc 9,9), no es propio del vocabulario anastasiológico de la Comunidad postpascual, cuya preferencia por el verbo "egéiro" es evidente ${ }^{12}$. Todas estas ausencias de vocablos y temas específicos de la fe cristiana son claros indicios de que aquella tradición evangélica no es producto de la Comunidad postpascual: ¡Su origen es anterior a Pascua!

c) Así lo insinúa ya el matiz palestinense de dicha tradición o su localización en el escenario geográfico del ministerio de Jesús. Ese transfondo refleja ya, sin duda, los numerosos semitismos y arameísmos detectados en el texto de la tradición evangélica ${ }^{13}$. Por lo demás, la incierta localización del

6. Cf. G. Dalman, Die worte Jesu, Leipzig 1930, 276-78; R. H. Fuller, The foundations of NT christology, London 1965, 155s (trad. españ., 163s); F. HAHN, Christologische Hoheitstitel (FRLANT 83), Göttingen ${ }^{31966,76-81.95 . ~}$

7. "Pedro y Juan y Santiago" (Act 1,13) o "Santiago y Cefas y Juan" (Gál 2,9).

8. "Juan": cf. Act 3, 1. 3. 11. 19; 8,14; Gál 2,9. "Santiago": cf. Act 12, 2. 17; 15, 13-21; 21, 18-25; Gál 1, 19; 2,9; 1 Cor 15,7.

9. R. PESCH, o.c., II 71.

10. J. JEREMIAS, Neutestamentliche Theologie, Gütersloh 1971, 40 (trad. españ., 45).

11. $\mathrm{Rm} 12,2 ; 2$ Cor 3,18 .

12. Cf. S. SABUGAL, El vocabulario anastasiológico del NT: RevAg 30 (1989) 385-401: 388 (n-14). 394 (n. 64).

13. Cf. supra, nn. 8-19. 
"monte alto" (v. 2) se sitúa sin duda en Galilea 14. A ese escenario palestinense remite asimismo la mención de "Elías con Moisés" (v. 3), dos figuras culminantes de la literatura rabbínica y de la religiosidad judaica 15 . Y si los "vestidos... blancos" del Jesús transfigurado (v. 3) evocan la mención de los "vestidos gloriosos" de los justos [salvados] por apócrifos judeo-palestinenses 16, el verbo "anístemi" (Mc 9,9) traduce sin duda el respectivo "qaem" [hebr. "qûm"] de anastasiológico vocabulario propio de la literatura rabbínica ${ }^{17}$. El colorido palestinense de la tradición evangélica es pues innegable.

d) Añadamos seguidamente, que los datos sustanciales de dicha tradición judeo-cristiana sintonizan perfectamente con el habitual modo de hablar y obrar, característicos del Jesús histórico. Típicos de su vocabulario es el innovador uso del introductorio vocablo "amén" (=en verdad), para corroborar sus palabras (v. 1a) ${ }^{18}$, así como la expresión "el reinado de Dios" y, concretamente, "ver el reinado de Dios" (v. 1b) 19; también "el Hijo del hombre" (v. 9) es una autodesignación habitual o "título firmemente anclado en las palabras de Jesús" ${ }^{20}$, cuyo preanuncio de su resurrección mediante

14. Tras la confesión mesiánica de Jesús por Pedro en "Cesarea de Filipo" (Mc 8,2729par) y su transfiguración "después de seis días" en "un hombre alto" (Mc 9,2par), el Maestro se encuentra en "Galilea" (Mc 9,30=Mt 17,22) y, por tanto, aquel "monte" está en esta región o, en todo caso, "muy lejano" de Cesarea de Filipo (G. Dalman, Orte und Wege Jesu, Gütersloh ${ }^{4} 1924$ [repr. Darmstadt 1967], 216-19:216). Por lo demás, los "seis días" pueden designar "una semana" judaica (cf. Éx 24,16) en "la tradición" evangélica: K. L. SCHMIDT, o.c., 222s; así también G. DALMAN, o.c., 216. Sobre el monte de la Transfiguración, cuya identificación con "el Tabor" ignora ORIGENES (s. III) y de la que duda EusEBIo C. (s. IV), atestiguada primeramente por san Cirilo J. (Cat. XII 16) y luego por san Jeronimo (Ep. 46,12; 58,8; 108,13), cf.: F. M. ABEL, Géographie de la Palestine, I, Paris ${ }^{3} 1967,353-57$ : 355ss; C. KoPP, Die heiligen Stätten der Evangelien, Regensburg ${ }^{2} 1964,299-306$; ID., Tabor: LThk IX 1268s (bibliogr.); A. RollA, Tabor: EncBib VI 845-48.

15. Según el palestinense R. Johannan ben Zakkai (s. I. d. C.) “dijo Dios a Moisés” que, "cuando envíe al profeta Elías, debéis venir los dos juntos" (cf. P. Volz, Die Eschatologie der jüdischen Gemeinde, Tübingen 1934 [repr. Darmstadt 1966], 197; la antigüedad de este testimonio, sin embargo, es insegura y, por lo demás, "con Elías o en relación con el Mesías no es mencionado Moisés en la más antigua literatura judaica": STR.-BILL., 756.

16. I Hen 62,15s; 2 Hen 22,8 (cf. STR.-BILL., I 752). El origen palestinense de I Hen es reconocido: cf. R. H. CHARLES, The Apocripha and Pseudoepigrapha of the OT, II, Oxford 1968, 171-80; F. Corriente-A. Piñero, Libro I de Henoc: "Apócrifos del AT" (dir. A. Diez Macho), IV, Madrid 1984, 21-25.

17. Cf. S. SABUGAL, La fe del Judaísmo antiguo en la resurrección de los muertos: RevAg 30 (1989) 143-54: 153, n. 54.

18. Cf. G. Dalman, Die Worte Jesu, 185-87; STR.-BILL., I 242-44: 243s; J. Jeremias, Abbá, Göttingen 1966, 148-51 (trad. españ., 105-9); ID., o.c., 43s (trad. españ., 50s).

19. Cf. G. Dalman, o.c., 83-119; J. JeREMIAS, Theologie, 40-43 (trad. españ., 64-50); S. SABUGAL, Abbá, 482-530: 483s. "Ver el reinado de Dios" es uno de los "giros, que no encuentran paralelos... en las [respectivas] expresiones del judaísmo contemporáneo": J. JEREMIAS, o.c., 41-43: 41 (trad. españ., 48-49: 48); cf. G. DALMANN, o.c., 84-108; todos los respectivos 
el verbo "qûm" no es extraño a su lenguaje 21. Tampoco lo es a la enseñanza del Jesús histórico: En ella se enraiza tanto el preanuncio de su resurrección (v. 9b) 22 y la prohibición de que los discípulos no divulguen "lo que vieron" ${ }^{23}$, como su preanuncio sobre la futura "visión" del "reinado de Dios" por "algunos de" aquéllos antes de "gustar la muerte" (v. 1) 24; sintonizando, por lo demás aquella profecía con su característico mensaje sobre la ya por él inaugurada presencia de aquel reinado divino ${ }^{25}$. Aquella prohibición y preanuncio, que literaria y temáticamente incluyen todo el relato tradicional sobre la transfiguración de Jesús (vv. 1. 9), están pues sólidamente anclados en la enseñanza histórica del Maestro. Lo que garantiza - no prueba- la sustancial historicidad del evento central o de la "transfiguración" y su "visión" por los tres elegidos discípulos: ¡La realidad del marco presupone la del cuadro! Un presupuesto corroborado por el significado mismo de la Transfiguración, como prolepsis o adelanto de la Resurrección. Esa interpretación unánime de aquélla por los cinco testimonios literarios 26 y que, por tanto, tiene toda garantía de autenticidad histórica, sintoniza sin duda con la pedagogía normal de Jesús o de quien reiteradametne confirmó con un gesto su previa enseñanza 27 e introdujo ésta con aquél 28: Que tras haber preanunciado su resurrección y antes de hacerlo por segunda vez ${ }^{29}$, Jesús confirmase y preparase aquel preanuncio con un gesto anastásico, se ajusta ciertamente a su habitual praxis. Con ésta se armoniza también la elección de "Pedro, Santiago y Juan" como testigos del evento (v. 1), elegidos asimismo por el Maestro - y en calidad de tales - a raíz de otros dos eventos culminantes

testimonios de la literatura judaica son tardíos (cf. G. Dalman, o.c., 89), de modo que la aserción de Jesús (v. 1) nos ha conservado "una antiquísima palabra" suya: J. JEREMIAs, o.c., 103 (trad. españ., 123).

20. J. JEREMIAS, Theologie, 246-63: 254 (trad. españ., 300-20: 309).

21. Cf. Mc 8,$31 ; 9,31 ; 10,34$ (=Lc 18,33).

22. Lo usó ya el Jud. palestinense. Supra, n. 17. Las mencionadas profecías de Jesús sobre su resurrección (supra, n. 21) son sustancialmente históricas: cf. S. SABUGAL, Credo. La fe de la Iglesia, Zamora 1986, 499 (bibliogr.); H. F. BAYER, Jesus, predictions of Vindication and Resurrection (WUNT 20), Tübingen 1986, 154-81.214-16. 254s.

23. Ese "secreto mesiánico", impuesto por el Maestro tras muchos de sus milagros o "signos" salvadores (cf. Mc 1,44-45par; 5; 37-43par; 6,45-46 [=Jn 6,15); 7,37; 8,26; Mt 9,30; 12,16; Jn 5,8. 13 etc.) es una definida característica del obrar propio del Jesús histórico: cf. X. LÉON-DufOur, Les Évangiles et l'histoire de Jésus, Paris 1963, 383-85 (trad. españ., 388-40);

V. TAYLOR, Mark ${ }^{2} 123$ s (trad. españ. 138).

24. Cf. S. Sabugal, Abbá. La Oración del Señor, Madrid 1985, 514-16 (bibliogr.).

25. cf. bibliogr.

26. Mc, Mt, Lc y 2Pe. (cf. supra).

27. Cf. Mc 2,5-11par; 3, 1-6; Mt 11,4-6 (=Lc 7, 21-23); Lc 14, 1-6; Jn 9, 4-6 etc.

28. Cf. Mc 2, 15-17par; 3,22-30par; 4,35-40par; Lc 7,36-50; 19,5-10; Jn 5, 6ss. etc. 
-resurrección de la hija de Jairo y crisis getsemaníaca- de su ministerio ${ }^{30}$. Por lo demás, Quien en "el monte" eligió a los Doce y oró ${ }^{31}$, también pudo "ser transfigurado ante" los tres elegidos discípulos en "un monte alto" (v. 1); cuya tradicional identificación con "el Tabor" no es geográficamente segura, pero sí es posible ${ }^{32}$.

El conjunto de los mencionados criterios de historicidad muestra que la primitiva tradición judeo-cristiana sobre la Transfiguración no es producto de la Comunidad post-pascual: Su múltiple testimonio y su discontinuidad tanto con el judaísmo contemporáneo como con la literatura específicamente cristiana, su colorido palestinense así como su sintonía con el lenguaje, enseñanza y habitual praxis del Maestro nazaretano son indicios objetivos de que, al nivel original, aquella tradición no sólo "informa sobre un estadio primitivo de la cristología" post-pascual ${ }^{33}$, sino se enraiza en un evento histórico de Jesús ${ }^{34}$.

2) Cuyo prístino significado y mensaje no es ciertamente fácil de precisar. Tampoco es imposible. Ya hemos afirmado, que la unánime interpretación de la Transfiguración por sus cinco testimonios literarios como anticipación o prolepsis de la Resurrección 35 tiene toda garantía de autenticidad histórica: Como, según la literatura veterotestamentaria y su respectiva paráfrasis targúmica del judaísmo palestinense, Moisés fue transfigurado en cierto modo por Dios, pues tras hablar con Él "resplandecía el brillo de su rostro" ${ }^{36}$, pudo Jesús "ser transfigurado" profundamente por Dios y ofrecer así a sus tres elegidos discípulos un adelanto de su transfigurante resurrección, no sin confirmarles en su seguimiento la "audición" de la "voz" divina o su declaración del Transfigurado como "el Hijo amadísimo" de Dios o su filial Siervo mesiánico y el nuevo Moisés (cf. supra). Por lo demás, esa corporal

29. Mc 8,31par; 9,9b (=Mt 17, 9b): Sobre la autenticidad histórica de estas profecías anastásicas, cf. supra, n. 22.

30. Mc 5,37 (=Lc 8,51); 14,33 (=Mt 26,37).

31. Mc 3,13 (=Lc 6,12); 6,46=Mt 14,23.

32. Cf. C. KopP, o.c., 299s; M.-J. LAGRANGE, Marc 233. Un amplio, detallado y documentado análisis, al respecto, ofrece E. DABRowsKI, o.c., 52-63.

33. Contra R. PESCH, Markus, II 81; así también; J. GnILKa, Markus, II 36s.

34. Así con: J. BlinZLER, o.c., 126; X, LÉon-DuFour, o.c., ("Études...)107. trad. españ., 104; E. NARDONI, o.c., (supra, n. 5), 139.

35. Una interpretación prolongada por la exégesis patrística, pues la mayor parte de los Padres griegos y latinos relacionan la Transfiguración con la Resurrección: cf. J. A. McGUCKIN, o.c., supra *), 99-128: 122-25 (textos patrísticos: 145-322).

36. Éx 34, 29s es parafeseado así por TgPIEX 34, 29-30. La antigua apocalíptica judaica nutría la convicción de que "los rostros" de los elegidos "brillarán de júbilo" en el cielo (1Hen 51,5; cf. 38,4; 39,7; 62,15; 104,2; 2 Hen 22, 8-10 etc): cf. STR.-Bill., I 752. 
"transformación" irradiante de Jesús y la audición de la "voz" divina son otros tantos sobrenaturales fenómenos místicos, históricamente comprobados en la vida de muchos santos cristianos: Su oración contemplativa se tradujo no rara vez en éxtasis, frecuentemente acompañados por "efluvios luminosos" de sus cuerpos "iluminados de una belleza celestial" propia de "una auténtica transfiguración" 37, así como por "audiciones sobrenaturales" y reveladoras de verdades ocultas o secretos divinos ${ }^{38}$. Jesús, orante asiduo y paradigmático ${ }^{39}$, pudo experimentar aquellos "transformantes" efectos de su contemplativa unión con Dios, "mientras oraba" (Lc 9,29) y como adelanto de lo que luego caracterizará a su glorioso cuerpo resucitado: ¡Él es el primer y paradigmático extático del Cristianismo! Una experiencia extática, por lo demás, en función de sus tres elegidos discípulos o como hemos indicadopara reafirmarles en el seguimiento del Maestro, al ofrecerles una prolepsis o -adelanto de su Resurrección. Lo que responde ciertamente al probable contexto histórico del evento. Ya el primer preanuncio de Jesús sobre su pasión, muerte y resurrección o su identificación con la preanunciada misión del mesiánico "Siervo de Dios" sufriente y glorificado ${ }^{40}$ suscitó la enérgica oposición - “ino será así!"- de Pedro y su no menos vigoroso reproche "¡atrás, satanás!" - del Maestro ${ }^{41}$; es pues normal, que su inmediata enseñanza sobre las duras condiciones - "autorrenunciarse" y "tomar la propia cruz" o "perder la propia vida" - para "seguirle" y "salvarse" ${ }^{42}$, asustase o desconcertase profundamente a los discípulos. Una turbación, sin embargo, seguidamente lenificada y superada por Jesús con su segura promesa - “en verdad os digo"- sobre la "visión" del "reinado de Dios" por "algunos" de aquéllos, antes de morir 43: ¡ $\mathrm{Su}$ seguimiento por la oscura senda de la cruz

37. A. FARges, Les phénomènes mystiques, II, Paris, 284-94; A. RoYo MARIN, Teología de la perfección cristiana, Madrid 1958,697. 860s; cf. también: A. SAUDREAU, L'état mystique, Paris 1921, 190-212; J. LOPEZ GAY, Mystique: DS IV 1983-1902: 1897s.

38. Cf. A. FARGES, o.c., II 34-42; A. SAudreaU, o.c., 212-22; A. Royo MARIN, o.c., 81924. Varios autores valoran la Transfiguración como una experiencia mística de Jesús (A. FARGES, o.c., II 36.285; A. Royo MARIN, o.c., 860. Cf. A. OEPKe, Extasis: ThWNT, II 454; V. TAYLOR, Mark $^{2}$ 388). En todo caso, los místicos del cristianismo fueron "imitadores y continuadores originales, aunque incompletos, de lo que consumadamente fue el Cristo de los Evangelios" (H. Bergson, Les deux sources de la morale et de la religion, Paris 1932, 238 ="Oeuvres", Paris 1970, 1179) y el Jesús histórico, en cuyo mensaje se enraiza sin duda la indiscutible "mística paulina y joannea". cf. R. SchNACKEnBURG, Mystik. II. In der Heligen Schrift: LThk VII 733s; R. PENnA-B. Maggioni, "La Mística", I (ed. ED. E. Ancilli-M. Paparozzi), Roma 1984, 181-250 (bibliogr.)

39. Cf. S. Sabugal, $A b b a ́, 339-49$ (bibliogr., 339, n.6).

40. Mc 8,31 par: cf. J. JeREMIAs, Paîs Theoû: ThWNT V 704, n. 405.

41. Mc 8, 32-33=Mt 16, 22-23.

42. Mc 8,34-35par.

43. Mc 9,1par. 
estará iluminado con la experiencia personal o visión del señorío de Dios sobre la muerte, efectivamente anticipado en la anastásica "metamorfosis" o "transfiguración" del Maestro "vista" por los tres elegidos discípulos! En este sentido, fue, pues, aquélla un preanuncio fáctico de que la previa profecía de Jesús sobre su pasión y muerte culminará efectivamente con su resurrección: ¡No deben temer quienes le sigan hacia el preanunciado cumplimiento sobre la pasión, muerte y resurrección del mesiánico "Siervo" de Dios! Pues, por lo demás, la inicial vocación bautismal de Jesús a cumplir la misión del "Siervo" mesiánico también fue confirmada entonces por la proclamación de Dios sobre su "Hijo amadísimo" o filial Siervo 44: Esa divinamente autoritativa proclamación garantizaba evidentemente a los seguidores del Maestro la verdad de su preanuncio anastásico y, a la vez, les exhortaba también - “jescuchadle!"- a tomar en serio su previa enseñanza sobre las condiciones para seguirle.

3) No podemos concluir estos análisis sobre el evento histórico de la Transfiguración y su significado prístino, sin, subrayar la siempre vigente actualidad de su mensaje para el creyente de hoy y de mañana. Más o menos conscientemente anhela todo hombre metamorforsearse o transfigurarse en un ideal, que refleje y resuma el modelo de su aspiración existencial. Y es natural. Pues, cuando aquel anhelo no es un alienante rechazo de la propia historia o una despersonalizante fuga del propio yo, expresa en sí el natural instinto humano de autosuperación: De ser en plenitud lo que —el paradigma humano- incipiente y devenirmente es. También el cristiano tiene su acabado modelo: Cristo, "el hombre nuevo" justo y santo 45 o en todo fiel a "la voluntad del Padre" como su filial Siervo" 46, por aquel, "enviado al mundo" y "venido" a él "para hacer la voluntad de Quien lo envió" y, a la vez, "servir" a los hombres con el "don de su vida en rescate por todos" ${ }^{4}$. De ese doble servicio complementario se nos propuso Él como paradigma "¡aprended de mí!" - inigualable o nos "dio ejemplo", tras conferirnos su Espíritu para poder imitarlo ${ }^{48}$. Toda la vida cristiana es pues una incesante

44. Mc 1,11par+9,9par (=Is 42,1). Sobre el significado histórico del bautismo de Jesús (Mc 1,10-11par) como vocación a cumplir la preanunciada misión del "Siervo de Dios" (Is 42,1), cf. J. Jeremias, Theologie, 56-62 (trad. españ., 67-74); así también: P. BenoIT, Jésus et le Serviteur de Dieu: "Jésus aux origines de la Christologie" (ed. J. Dupont), Gembloux 1975, 111-40: 121; S. SABUGAL, Abbá, 505. 720; ID., La Iglesia, sierva de Dios. Zamora 1987, 54s.

45. Ef 2,15; 4,24; $\operatorname{Col} 3,10$.

46. Jn 8,29 (=6,24; 4,34; Hebr 10, 5-7); Fil 2, 6-8; Mc 1,11par; 9,7; Mt 12, 15-21.

47. Gál 4,4; Jn 3,16;6,38; Mc 10,45par.

48. Mt 11,29; Jn 13,15; 14, 12-14. 
imitación de Cristo, a impulso del Espíritu: Una permanente "metamorfosis" o transfiguración de nuestra "mente, para poder discernir" en los eventos de la propia historia "la voluntad de Dios" y agradarle en todo, pues "reflejamos - como en un espejo- la gloria del Señor" Jesús y "nos metamorfoseamos en esa misma imagen, según la acción del Espíritu del Señor" 49. La existencia cristiana es, pues, fundamentalmente transfiguración o metamorfosis: Inaugurada ésta en la bautismal transformación de los antes "muertos por el pecado" en la "vida nueva" o imagen del Resucitado 50, se prolonga en la tensión constante por metamorfosearnos (cf. supra) o cambiar la forma del adámico "hombre viejo" por la del crístico "Hombre nuevo" 51. Una transfiguración existencial, cuya meta final y acabado logro tendrá lugar con nuestra integral metamorfosis parusíaca — “itodos seremos transformados!”- y anastásica en "la imagen del hombre celeste" 52. A esa meta, sin embargo, se llega por el "estrecho sendero" de "la propia cruz" diaria 53. Y la "transfiguración" del Señor nos estimula a recorrerlo. Pues quienes, tomando aquélla sigamos al Jesús transfigurado o al mesiánico Siervo de Dios anticipadamente glorificado por el camino del servicio a Dios y a los hombres, - del que se nos propuso como modelo y del que "nos dio ejemplo" a todos, para "tener sus mismos sentimientos" o "seguir sus huellas" 54 , podemos estar seguros de no caminar solos ni a oscuras: ¡Nos acompañará siempre Quien prometió "estar con nosotros todos los días" 55 y, ya durante el seguimiento, iluminará Él nuestra crucífera marcha con el fulgor de su resurrección o transfigurará nuestra situación de cruz con la gloria de su señorío sobre toda realidad de sufrimiento y de muerte! Por eso la Transfiguración es "prototipo de la experiencia mística" 56 o del encuentro personal, que todo seguidor del Crucificado puede y debe tener -en el aquí y ahora de su historia- con el Resucitado: ¡Una experiencia o encuentro con "el poder de su resurrección”, que nos alienta en la transfigurante "carrera" cristiana de "comunión con los padecimientos" de Cristo, hasta que, metamorfoseados en su imagen o transformados por su gloria (cf. supra), "alcancemos el premio a que Dios" nos destina o "la salvación"! 57. Es lo que suplica la liturgia de la Iglesia, pidiendo a

49. $\operatorname{Rm~} 12,2 ; 2$ Cor 3,18 .

50. $\operatorname{Rm} 6,2-11 ; \operatorname{Ef} 2,5-6$.

51. Ef 4, 22-24; $\operatorname{Col} 3,9-10$.

52. Cf. 1 Cor $15,49.51-52$.

53. Mt 7,14par; Lc 9, 23-24par.

54. Mt 20, 26-28par; Jn 13, 12-15; Fil 2,5ss; 1Pe 2, 21-24. A este respecto, cf S. SABugaL. Credo 949-51; ID., La Iglesia, 60-64.

55. Mt 28,20.

56. X. LÉON-DUfOUR, o.c., 122 (trad. españ., 119); cf. supra, n. 37-38.

57. Fil 3, 10-14; 1 Tes 5,9. 
"Dios que, en la transfiguración gloriosa de su Hijo... prefiguró admirablemente" nuestra "filiación divina", nos "otorgue que, oyendo la voz de su Hijo amado, merezcamos ser sus coherederos" 58 .

Santos SABUgAL

Instituto Patrístico "Augustinianum” Roma

58. Pablo VI, Missale Romanum, Ciudad del Vaticano 1975, 587 (=Oración colecta de la "Fiesta de la Transfiguración"). Sobre dicha festividad (6 agosto), celebrada en Oriente ya desde finales del s. v o principios del s. vI, cf. P. JounEL, Transfiguración del Señor: "La Iglesia en oración" (ed. A. G. Martimort), Barcelona ${ }^{21987, ~ 987-89 ~(b i b l i o g r .) . ~}$ 